Hongzhou Ma*, Hongwei Xie, Yaoning Wang and Chao Yan

\title{
Optimization of the treatment process of zinc leaching residue by using the response surface method
}

https://doi.org/10.1515/gps-2017-0043

Received April 1, 2017; accepted August 4, 2017; previously published online September 19, 2017

\begin{abstract}
The decrease in the zinc volatilization rate is usually due to the liquid phase, which is typically generated in the rotary kiln. The response surface model was built to analyze and explore the effects of carbon content, basicity, and holding time on the zinc volatilization rate and residue state. Moreover, the model was used to optimize the experimental conditions. The results showed that the effect of basicity on zinc volatilization rate was statistically significant, whereas the effects of carbon content and holding time were relatively small. The optimized process conditions were as follows: carbon content of $32 \%$, basicity of 3, and holding time of $30 \mathrm{~min}$. Under this condition, the zinc volatilization rate was $99.65 \%$, and the furnace residue was sintered, which proved to be beneficial to the subsequent step of iron extraction.
\end{abstract}

Keywords: response surface model; rotary kiln; zinc leaching residue.

\section{Introduction}

The hydrometallurgy process serves as the major route of zinc extraction, which contributes to over $80 \%$ of the zinc production all over the world. This process, however, produces great amounts of waste, particularly leaching residues. The residues from conventional acid leaching

\footnotetext{
*Corresponding author: Hongzhou Ma, School of Metallurgical Engineering, Xi'an University of Architecture and Technology, Xi'an, Shaanxi 710055, P.R. China; and Shaanxi Technological Institute of Metallurgical Engineering, Shaanxi Key Laboratory of Gold and Resource, Xi'an, Shaanxi 710055, P.R. China, e-mail: mhzwyn@126.com Hongwei Xie, Yaoning Wang and Chao Yan: School of Metallurgical Engineering, Xi'an University of Architecture and Technology, Xi'an, Shaanxi 710055, P.R. China; and Shaanxi Technological Institute of Metallurgical Engineering, Shaanxi Key Laboratory of Gold and Resource, Xi'an, Shaanxi 710055, P.R. China
}

still contain traces of valuable metals that can serve as secondary resources $[1,2]$. The reduction-volatilization in the rotary kiln is typically used to treat such residues to recover zinc [3], and the kiln residues can be used to recover iron in the subsequent step $[4,5]$.

The reduction-volatilization in the kiln usually reacts at about $1200^{\circ} \mathrm{C}$. This high temperature melts the low-melting point compositions in the residue, such as silicate, thus causing several problems. First, some of the non-reduction powder will be wrapped by the liquid phase, generating the outsourcing silicate melt shell with the powder. Meanwhile, some substances, such as zinc silicate, would also be generated in the melt. In turn, these can reduce the zinc volatilization rate in the kiln. Second, the kiln's internal diameter may be reduced because of the ring formed by the sintered melt. Hence, the kiln life and handling capacity are also reduced. Finally, some iron oxides from the leaching residue can produce iron silicate, which may be wrapped in the melt. Both iron oxides and iron silicate could not be reduced to magnetite, and the corresponding components become difficult to extract during the crushing process. These are the main reasons why it is difficult to recover iron from kiln residue, which leads to the low iron recovery rate.

Hence, it can be inferred that preventing the generation of the liquid phase is not only beneficial to the volatilization of zinc but it can also prevent furnace residue sintering. According to the ternary phase diagram [6], on the one hand, the melting point of zinc leaching residues rises when $\mathrm{CaO}$ content is increased within a certain range. On the other hand, the addition of $\mathrm{CaO}$ can reduce the Gibbs free energy of the reductive reaction.

Based on the above, the current work proposed to add the slagging agent to the zinc leaching residue, thus changing the basicity and improving the melting point, which can help avoid the abovementioned problems in the rotary kiln production process. In this paper, the Gibbs free energy of the reductive reaction was calculated, and the reduction process of changing conventional acid leaching residue's basicity was investigated by using the response surface method (RSM) [5, 7-10]. 


\section{Materials and methods}

\subsection{Materials}

According to previous X-ray powder diffraction (XRD) analyses, the leach residue used in the experiments contains $18 \%$ zinc, $6.3 \% \mathrm{SiO}_{2}$, and $1.76 \% \mathrm{CaO}$. The zinc in the residue is mainly in the form of zinc ferrate $\left(\mathrm{ZnO} \cdot \mathrm{Fe}_{2} \mathrm{O}_{3}\right)$ and a little bit of zinc sulfate $\left(\mathrm{ZnSO}_{4}\right)$. The $\mathrm{CaO}$ added as a slagging agent was analytical pure. The fixed carbon content of the reduction carbon powder was $78 \%$.

\subsection{Experimental procedure}

The zinc leaching residue was dried at $100^{\circ} \mathrm{C}$ and mixed proportionally with $\mathrm{CaO}$ and carbon powder. The reduction of the volatilization

Table 1: Parameters and their levels used for the response surface design.

\begin{tabular}{lrr}
\hline Parameter & \multicolumn{1}{r}{ Levels } \\
\cline { 2 - 3 } & \multicolumn{1}{c}{$\mathbf{1}$} & $\mathbf{1}$ \\
\hline Carbon content (wt.\%) & 20 & 50 \\
Basicity $\left(\mathrm{CaO} / \mathrm{SiO}_{2}\right)$ & 0.28 & 3 \\
Holding time $(\mathrm{min})$ & 30 & 60 \\
\hline
\end{tabular}

Table 2: Experimental conditions and results.

\begin{tabular}{|c|c|c|c|c|}
\hline No. & $\begin{array}{r}\text { Carbon content } \\
\text { (wt.\%) }\end{array}$ & Basicity & $\begin{array}{r}\text { Holding } \\
\text { time (min) }\end{array}$ & $\begin{array}{r}\text { Volatilization } \\
\text { rate of zinc (\%) }\end{array}$ \\
\hline 1 & 20 & 1.50 & 60 & 61.08 \\
\hline 2 & 30 & 0.89 & 45 & 74.72 \\
\hline 3 & 30 & 0.89 & 45 & 72.65 \\
\hline 4 & 30 & 0.28 & 45 & 70.17 \\
\hline 5 & 40 & 1.50 & 30 & 83.87 \\
\hline 6 & 30 & 1.50 & 45 & 79.24 \\
\hline 7 & 20 & 1.50 & 30 & 67.25 \\
\hline 8 & 40 & 0.89 & 45 & 78.84 \\
\hline 9 & 20 & 0.89 & 45 & 71.89 \\
\hline 10 & 40 & 0.28 & 60 & 67.34 \\
\hline 11 & 40 & 1.50 & 60 & 84.54 \\
\hline 12 & 30 & 0.89 & 30 & 76.20 \\
\hline 13 & 30 & 0.89 & 60 & 77.99 \\
\hline 14 & 20 & 0.28 & 30 & 63.97 \\
\hline 15 & 40 & 0.28 & 30 & 67.60 \\
\hline 16 & 20 & 0.28 & 60 & 69.79 \\
\hline 17 & 50 & 0.28 & 60 & 72.73 \\
\hline 18 & 50 & 3.0 & 30 & 99.56 \\
\hline 19 & 20 & 3.0 & 60 & 96.90 \\
\hline 20 & 35 & 3.0 & 60 & 99.79 \\
\hline 21 & 20 & 3.0 & 30 & 92.15 \\
\hline 22 & 50 & 3.0 & 60 & 99.77 \\
\hline 23 & 50 & 3.0 & 30 & 99.37 \\
\hline 24 & 50 & 0.28 & 30 & 70.12 \\
\hline
\end{tabular}

process of zinc was simulated in a ceramic crucible with a cover at $1200^{\circ} \mathrm{C}$ for a certain time; at the end of the experiment, the crucible was cooled to room temperature in the furnace. Next, the residue was taken out and weighed, after which the zinc content was analyzed by using the EDTA volumetric method (according to the China National Standard GB/T 14353.3-2010). This was done to calculate the zinc volatilization rate.

\subsection{Experimental design and results}

The response surface experiment design was carried out using the response surface design platform of JMP (USA), a data statistics software. Three parameters were considered (carbon content, basicity, and holding time) and the setting of each parameter is shown in Table 1 . The variable values of nos. 1 to 16 were designed by using the central composite design (CCD) and nos. 17 to 24 belonged to the extended experiments. The experimental results are shown in Table 2 .

\section{Statistical analysis and discussion \\ 3.1 Statistical analysis}

The stepwise regression method was chosen to analyze the experimental data in Table 2, and the quadratic response surface model was established after eliminating the nonsignificant items. The model for zinc volatilization rate is calculated by the obtained quadratic regression equation given by

$$
\text { Zinc volatilization rate } \begin{aligned}
(\%) & =82.108005+3.4303333 \mathrm{X}_{1} \\
& +14.440229 \mathrm{X}_{2}+0.4451064 \mathrm{X}_{3} \\
& -5.258419 \mathrm{X}_{1}^{2}+4.982143 \mathrm{X}_{2}^{2},
\end{aligned}
$$

where $\mathrm{X}_{1}, \mathrm{X}_{2}$, and $\mathrm{X}_{3}$ are equal to $\frac{\text { carbon content (wt.\%)-35 }}{15}$, $\frac{\text { basicity }-1.64}{1.36}$, and $\frac{\text { holding time }(\mathrm{min})-45}{15}$, respectively.

According to the analysis of variance and test for lack of fit (Table 3), this equation is suitable for expressing the model. The $\mathrm{R}^{2}=0.91$ and the high $\mathrm{F}$ value (35.0302) and low $\mathrm{p}$-value $(\mathrm{p}<0.0001)$ indicate that the fitting model is reasonable. Hence, the model can be used to analyze and optimize the process of zinc leaching in the rotary kiln. The $p$-value $(p>0.05)$ of the test for lack of fit also shows that the fitting model does not exhibit lack of fit. Table 4 shows the significance of each coefficient in the equation, which is determined by the p-value listed. As can be 
Table 3: Analysis of variance and test for lack of fit for the regression model.

\begin{tabular}{|c|c|c|c|c|c|}
\hline \multicolumn{6}{|c|}{ Quadratic response surface model of zinc volatilization rate $\left(R^{2}=0.91\right)$} \\
\hline Source & Df & Sum of squares & Mean square & F value & p-value \\
\hline \multicolumn{6}{|c|}{ Analysis of variance } \\
\hline Model & 5 & 3263.6160 & 652.723 & 35.0302 & $<0.0001$ \\
\hline Error & 18 & 335.3970 & 18.633 & & \\
\hline Total & 23 & 3599.0130 & & & \\
\hline \multicolumn{6}{|c|}{ Test for lack of fit } \\
\hline Lack of fit & 16 & 333.2365 & 20.8273 & 19.2801 & 0.0504 \\
\hline Pure error & 2 & 2.16050 & 1.0803 & & \\
\hline Total & 18 & 335.39698 & & & \\
\hline
\end{tabular}

Table 4: Significance test for the regression coefficients.

\begin{tabular}{lrrrr}
\hline Source & Df & Sum of squares & F value & p-value \\
\hline$X_{1}$ & 1 & 129.6178 & 6.9563 & 0.0167 \\
$X_{2}$ & 1 & 2628.0798 & 641.0431 & $<0.0001$ \\
$X_{3}$ & 1 & 3.4802 & 0.1868 & 0.6707 \\
$X_{1}{ }^{2}$ & 1 & 101.3841 & 5.4411 & 0.0315 \\
$X_{2}{ }^{2}$ & 1 & 82.2455 & 4.4139 & 0.0500 \\
\hline
\end{tabular}

seen, the effects of the first term $X_{1}, X_{2}$ and the quadratic term $\mathrm{X}_{1}^{2}, \mathrm{X}_{2}^{2}$ on the response of zinc volatilization rate are significant. This means that the carbon content and the basicity are the main parameters affecting the rate of zinc volatilization, and do not indicate a simple linear relationship.

\subsection{Reduction mechanism}

Although the zinc ferrite in the zinc leaching slag cannot easily undergo thermal decomposition, they tend to be easily decomposed when added carbon or under the conditions of carbon monoxide atmosphere [11-13]. This can be explained by the following reactions expressed by Equations (2) and (3). Another zinc-bearing phase in the slag can also be reduced by carbon as shown in Equations (4) and (5).

$$
\begin{gathered}
3 \mathrm{ZnO} \cdot \mathrm{Fe}_{2} \mathrm{O}_{3}+\mathrm{C}=3 \mathrm{ZnO}+2 \mathrm{Fe}_{3} \mathrm{O}_{4}(\mathrm{~s})+\mathrm{CO}(\mathrm{g}) \\
3 \mathrm{ZnO} \cdot \mathrm{Fe}_{2} \mathrm{O}_{3}+\mathrm{CO}(\mathrm{g})=3 \mathrm{ZnO}+2 \mathrm{Fe}_{3} \mathrm{O}_{4}+\mathrm{CO}_{2}(\mathrm{~g}) \\
\mathrm{ZnO}(\mathrm{s})+\mathrm{C}(\mathrm{s})=\mathrm{Zn}(\mathrm{g})+\mathrm{CO}(\mathrm{g}) \\
2 \mathrm{ZnO}(\mathrm{s})+\mathrm{C}(\mathrm{s})=\mathrm{Zn}(\mathrm{g})+\mathrm{CO}_{2}(\mathrm{~g}) .
\end{gathered}
$$

The values of the Gibbs free energies in Equations (2) to (5) can be respectively estimated by using Equations (6) to (9). The values at the temperature over $1060.85^{\circ} \mathrm{C}$ are less than zero, indicating that the reduction reaction with carbon can be carried out spontaneously with a temperature higher than $1060.85^{\circ} \mathrm{C}$. Thus, the effect of carbon will not be significantly larger when the temperature reaches this condition.

$$
\begin{aligned}
\Delta \mathrm{G}_{1}{ }^{\Theta} & =133888-224.28 \mathrm{~T} \\
\Delta \mathrm{G}_{2}{ }^{\Theta} & =-28869.6-56.50 \mathrm{~T} \\
\Delta \mathrm{G}_{3}{ }^{\Theta} & =344552.4-281.17 \mathrm{~T} \\
\Delta \mathrm{G}_{4}{ }^{\Theta} & =526347.2-394.55 \mathrm{~T}
\end{aligned}
$$

\subsection{Optimization}

The above response surface quadratic model was applied to explore the best combination of the three variables. The changes of zinc volatilization rate with different selection of variables are shown in the prediction profiler (Figure 1).

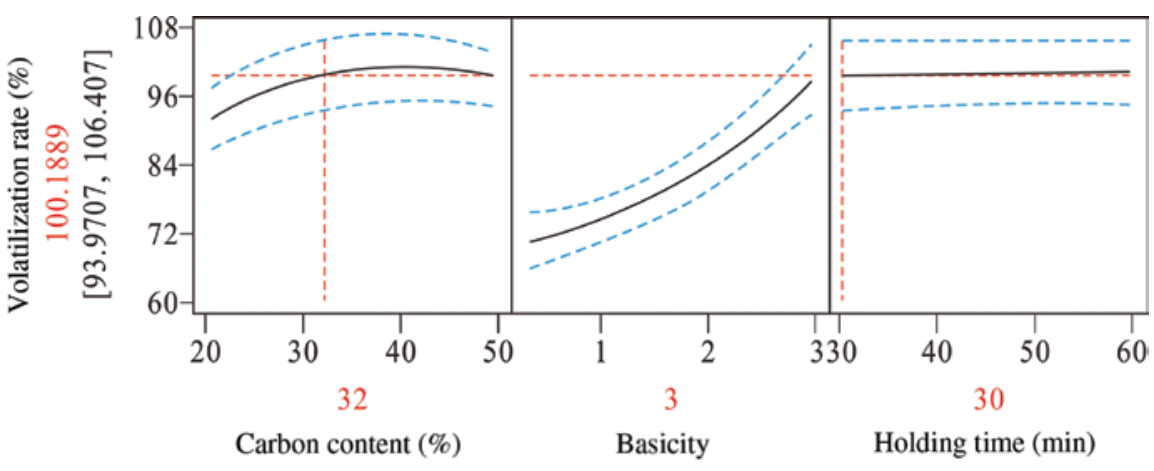

Figure 1: Prediction profiler for the zinc volatilization rate. 
As can be seen, the rate tends to be high with the increase of content of carbon. Until the content of carbon reaches $32 \%$, the rate change is very small. While basicity has a more significant effect on the zinc volatilization rate, there exists a nearly linear relationship between them when basicity is higher than 1.5. Moreover, the holding time had little effect on zinc volatilization. Thus, it can be concluded that the zinc volatilization rate could achieve almost $100 \%$ with carbon content of $32 \%$ carbon, basicity of 3 , and holding time of $30 \mathrm{~min}$.

\section{Verification}

The selected optimal conditions of 32\% carbon, basicity of 3 , and holding time of $30 \mathrm{~min}$ for the optimum response values were tested. The experimental results indicated that the zinc volatilization rate reached $99.65 \%$ and obtained a powdery residue under the optimal conditions.

\section{Conclusions}

Adding $\mathrm{CaO}$ into zinc leaching residue is technically feasible in optimizing the process of reduction volatilization in e rotary kiln. Adding $\mathrm{CaO}$ can effectively prevent the sintering of the charge, thereby reducing the kiln ring. This result is beneficial to the next iron extraction step and can ultimately help improve the service life of the kiln.
Under the optimized conditions, the volatility of zinc can reach $99.65 \%$. Compared with the current rotary kiln zinc volatilization rate, it increased by $5 \%-6 \%$ to improve the metal recovery rate, thus effectively preventing the generation of residues in the volatile liquid phase.

Acknowledgments: We wish to thank School of Metallurgical Engineering, Xi'an University of Architecture and Technology for the support it has provided.

\section{References}

[1] Wei W, Chen H, Chen Q, Liu Y. Hunan Nonferrous Metals. 2012, 70, 37-39.

[2] Jha MK, Kumar V, Singh RJ. Resour. Conserv. Recy. 2001, 33, 1-22.

[3] Yunkang F. Sichuan Nonferrous Metals. 2003, 35-38.

[4] Liu, Tan J, Liu C, Yin Z, Chen Q, Zhan P, Liao Z. Chinese Journal of Nonferrous Metals. 2015, 25, 1978-1986.

[5] Li Y, Liu H, Peng B, Min X, Hu M, Peng N, Yuang Y, Lei J. Hydrometallurgy 2015, 158, 42-48.

[6] Zhonghua F, Yanling Z, Shiqi L, Yugang W. J. Wuhan Univ. Sci. Technol. 2010, 33, 113-119.

[7] Qin W, Li L, Zhan X, Chen X, Guo W, Li N. Natural Product Research and Development. 2011, 23, 314-319.

[8] Makadia AJ, Nanavati J. Measurement 2013, 46, 1521-1529.

[9] Sumic Z, Vakula A, Tepic A, Cakarevic J, Vitas J, Pavlic B. Food Chem. 2016, 203, 465-75.

[10] Yin X, You Q, Jiang Z. Carbohydr. Polym. 2011, 86, 1358-1364.

[11] Li M, Peng B, Chai L, Peng N, Yan H, Hou D. J. Hazard. Mater. 2012, 237-238, 323-30.

[12] Peng N, Peng B, Chai L, Liu W, Li M, Yuan Y, Yan H, Hou DK. Procedia Environ. Sci. 2012, 16, 705-714.

[13] Turan MD, Altundoğan HS, Tümen F. Hydrometallurgy 2004, 75, 169-176. 